\title{
APPLIED QUANTITATIVE METHODS IN MATERIALS HANDLING - A CASE STUDY IN THE MPMP HOSPITAL
}

\author{
Flavio Alberto Gomes da Silva \\ Faculdade de Tecnologia da Zona Leste, Brazil \\ E-mail: flaviobeto.gsilva@gmail.com
}

Submission: 08/03/2018

Accept: 29/03/2018

\section{ABSTRACT}

Quantitative methods is an important tool for a wide range of logistic processes, particularly in stock management operations such as handling and storage. Especially in a Hospital, in which it is essential to a good supply of materials and medicines that guarantee the agility required in meeting the demands of patients. The objective of the present work is to understand the process of separation and distribution of materials and medicines within a hospital storeroom and use quantitative methods for optimizing management and routing of its activities aimed at reduce the time of path between the stockroom to the Neonatal Intensive Care Unit (NICU), Surgery, Nursery and adult Intensive Care Unit of Hospital MPMP. For this, a literature search and a case study in a Hospital. The article presents a suggestion of improvement of routing and optimization of distribution processes, using Microsoft Solver. Which might verify that the implementation of this procedure is quite simple and the Hospital can deploy it with confidence that improvements will occur at the service level.

Keywords: Management; Modeling; Methods; Distribution; Optimization 
DOI: 10.14807/ijmp.v9i5.793

\section{INTRODUCTION}

The applications of quantitative methods may play an important role in addressing the issue of materials handling and storage. In the current scenario, with the fierce global competition, companies seek to stand out with the implementation of new processes, as has the need to respond with agility and speed to changes imposed by the markets.

The Organization and specialization of production activities result in surplus production that requires storage to ensure the integrity of the products. In addition, stocks of products in various stages of the production chain are needed to ensure supplies and reduce uncertainties. To ensure that the products stored are available and used is necessary to efficient drive to the destination where it will be consumed (FLEURY, 2007).

Polls show that the optimization of the logistics operations in warehouses represents vast improvement to the logistic processes (BAKER; CANESSA, 2009; GU, et al., 2007; ZHANGA; LAIB, 2010). With respect to internal logistics material handling of a warehouse is defined by Bowersox et al. (2006) as an activity of paramount importance to the Organization, as it involves from the receipt and storage of the product to your customer, dispatch rescue always seeking the lowest cost for the operation. Luna et al. (2011) States that the distribution of items within the warehouse, the types of equipment for handling and warehouse setting interfere directly in its operations.

In this context, the use of strategies to add value to any organization become useful. And inventory management, for example, is currently seen as a strategic part with direct influence in the relationship with customers, thus directly linked to the success of organizations. Furthermore, according to Ballou (2006), the cost of storage and movement can represent 20 to $40 \%$ of your value per year. In the hospital sector, storage and materials handling are activities that have an impact on cost and level of service due to the volumes of products.

The stock, in an organizational environment, for some time it was considered a restricted area to an operational role. However, the ancient form of how this area was portrayed has changed with globalization and currently, inventory management, combined with the technologies and strategic actions, optimizes the relationship 
between customers and suppliers, aiming the improvement of supply and increased level of service.

This paper presents a case study of separation processes and distribution of materials and medicines in a storeroom for the NICU, Surgery, Nursery and Adult $I C U$, considered the most critical areas of the Hospital MPMP. Especially for this Hospital, it is essential to keep a good supply of materials and medicines, ensuring the necessary agility in meeting the demands of patients.

The applications of quantitative methods consist in the form in which the materials and medicines are distributed, with the purpose to optimize the storage areas and greater efficiency in the process. In this study we used the technique of Lower path in the Solver add-in available for free in Microsoft Excel as a tool for obtaining the optimal configuration.

The premises were met primarily in a bid with a single worksheet, but it has not been possible to find a convergent solution. Given the graph of Distribution routes devised other Graphs for each separate target, since applying the Lower Path of a single source to multiple destinations is unworkable. This allowed to highlight the potential and limitations of the Microsoft Solver.

This work showed the importance of formulating a realistic model and a detailed critical analysis, which can be seen through the lack of viability of the first Graph and the success achieved by development of Graphs for each target.

The study aims to detail the management of inventory in the back room of a Hospital, studying the improvements in the materials handling process conducted through quantitative methods.

\section{LITERATURE REVIEW}

\subsection{Inventory management}

There are different theories in the literature regarding the management of stocks, Moura (2004) cites that stock is considered a set of stored goods, with its own characteristics and specific functions that meet the goals and needs of the company needs. So every item stored in a warehouse, shed, warehouse, shelf, drawer or cupboard to be used by the company in any of its activities, is considered an item of stock. 
On the other hand, Ballou (2006) describes that stocks are accumulations and raw materials, supplies, components, in-process materials and finished products that appear in numerous points of production and logistics companies. Inventories are usually found in warehouses, sheds, patios. The cost of maintaining the stock can represent $20 \%$ to $40 \%$ of your value per year. For this reason, carefully manage inventory levels is economically sensible. Which confirms the importance of adopting quantitative methods to increase your efficiency.

For Arnold (1999) the inventory management is a concept that is present in virtually all types of businesses, as well as in everyday life of the people. Since the beginning of your story that humanity has used a variety of resource stocks, in order to support your development and survival.

\subsection{Handling and storage}

The material is related to the flows of materials, refer to the paths traveled by products in different areas through which. I've basically storage is the storage of goods as efficiently as possible.

In the design of Ballou (2001), materials handling consists of the activities of loading, unloading, handling and storage, and filing of the application. The handling of products is the key to the productivity of the deposits, and if the storage activity more Labour-consuming. So the design of a deposit is a determining factor for the efficiency of handling operations (BOWERSOX; CLOSS, 2001).

Koster et al. (2006) highlight how basic objectives of maximizing the effective use of space, equipment, manpower and accessibility to materials, and minimizing the time availability of the applications.

$\mathrm{Gu}$ et al. (2007) state that the resources such as equipment, space and manpower need to be allocated among the various activities of a warehouse, and each activity must be carefully implemented, operated and coordinated to achieve the requirements of all system in terms of capacity, flow and service at the lowest possible cost.

Studies conducted by Mc (2005) cites that the man has been trying to solve the problem of moving materials to make your job to get up, move from one place to another and carry more easy, fast and secure. The move is an activity that has a strong relationship with the storage, which is the generic name and broad that it 
INDEPENDENT JOURNAL OF MANAGEMENT \& PRODUCTION (IJM\&P)

http://www.ijmp.jor.br

v. 9, n. 5, Special Edition IFLOG 2017

ISSN: 2236-269X

DOI: 10.14807/ijmp.v9i5.793

includes all activities of a location for the temporary guardianship and the distribution of materials for tanks, warehouses, distribution centers etc. and is closely related to the material.

Other studies investigating the importance of handling and storage costs indicate that the flow of these processes represent $30 \%$ to $35 \%$ of the total logistics costs, and your participation has been growing in recent years. In addition, the warehouse is the bond that unites the production or the supplier to the consumer.

Most companies develop many improvement projects considering the cost and level of service in handling and storage. And in most cases organizations faced with several alternatives that can be chosen for implementation.

In this work it is suggested the application of quantitative methods as a tool to support in decision-making, taking into consideration the best use of resources for handling, optimization of storage areas and increased speed of process.

\subsection{Quantitative techniques applied to inventory management}

More recent attention has focused on provision of Hillier and Lieberman (2010) warn that the techniques to manage the stocks are changing between organizations. Japanese companies were pioneers in introducing the system of justin-time inventory that emphasizes planning and programming for the materials arrive extremely in time for your use, and inventories are reduced to levels to strictly necessary. Another tool that is being used for competitive gain is the application of operational research techniques, to optimize their inventory policies through the following steps:

- Formulate a mathematical model to describe the behavior of the stock system;

- Pursue a policy of great stocks in relation to this model;

- Use a computerized information processing system to maintain a record of the current inventory levels;

- Use this record to current inventory levels, apply the policy of great stocks to signal when and at what levels to replenish stocks.

Currently, Microsoft Excel, among other systems, is able to solve problems of operational research through the linear programming, covering a relatively large range of Logistics problems. 
This view is supported by Tadeu (2008) the use of mathematical models used in inventory management fully meets "expectations of production or consumption of the organizations, with maximum efficiency, reduce costs and drive time".

Together, these studies indicate that the application of models allows making improvements of implementation of development whereas the storage service levels and movement. It can be observed that quantitative inventory methodologies are important to a good performance in the industry, because it presents itself as an excellent tool to aid in decision-making to managers.

\section{METHODOLOGY}

For this study we chose to adopt a case study, because your goal is to better understand the process of separation and distribution of materials and medicines within a hospital storeroom. According to Gil (1991), the case study is characterized by extensive and in-depth study of a few objects, in order to allow broad and specific knowledge of the same.

The case study was conducted in a private health institution, located in the municipality of São Paulo. This enabled an empirical analysis of the importance in the use of mathematical models used in inventory management.

Thus, the study made possible the description and understanding of the logistics supply chain process and distribution of materials in various sectors within the hospital environment. The present research was divided into the following steps:

- A survey was conducted of the sectors and stocks to be supplied by the warehouse and their main problems, involving collection and analysis of information making it possible to contextualize and deepen the knowledge of object of study;

- Subsequently, the data for the study were collected through documents from the hospital;

- Finally, an interview with General hospital Pharmacist Coordinator accompanied by visits to the process, being explored the process of distribution and supply of materials and medicines.

This research took place between January to May 2017. 
DOI: 10.14807/ijmp.v9i5.793

\section{STUDY OF CASE}

The case study was conducted in the MPMP Hospital, which is a subsidiary of the SJ Group. Founded in 1936 the maternity unit is headquartered in the city of São Paulo (SP), beautiful view.

For the study, data was collected regarding the sector of distribution of materials and medicines to the Hospital during the year 2017 in the periods from January to may. It is a large enterprise of the branch hospital works with approximately 4000 items specific to the area of health; the inputs, medicines, equipment and tools, electrical parts, electronics and common materials such as cleaning products, Office and others.

To facilitate the understanding of this case study, your presentation was divided into two parts: (i) presentation of the procurement process; (ii) discussion of the data collected with motherhood and observation of the researchers.

\subsection{Procurement process}

Starts with the requisition of materials or medications to stock (warehouse) via system, prints the request, separation, Conference, packaging, and low in the system, and transported to your recipient. This process is repeated weekly until the stock reaches the limit point, your need to be replenished by the matrix.

Replenishment occurs once a week, sporadic cases of solicitation in the array occur when certain product just before refueling.

On Tuesdays it's done a survey via the dispensation of medicines (pharmaceutical Act the user guidance and provision of medicines) in all sectors and sub stocks, generating a report that is going to position the outputs and the current stock the storeroom. Through this report are faced exits and current stock to make the request to the array with intention of making replacements (every Wednesday).

Made the request is sent to the array where is typed and downloaded to the system, generating a report of transfer between companies, prints of this report, a two-way will be to make the separation and the other will be sent the branch along with the materials: be separated, packed the various and packed in shipping. 


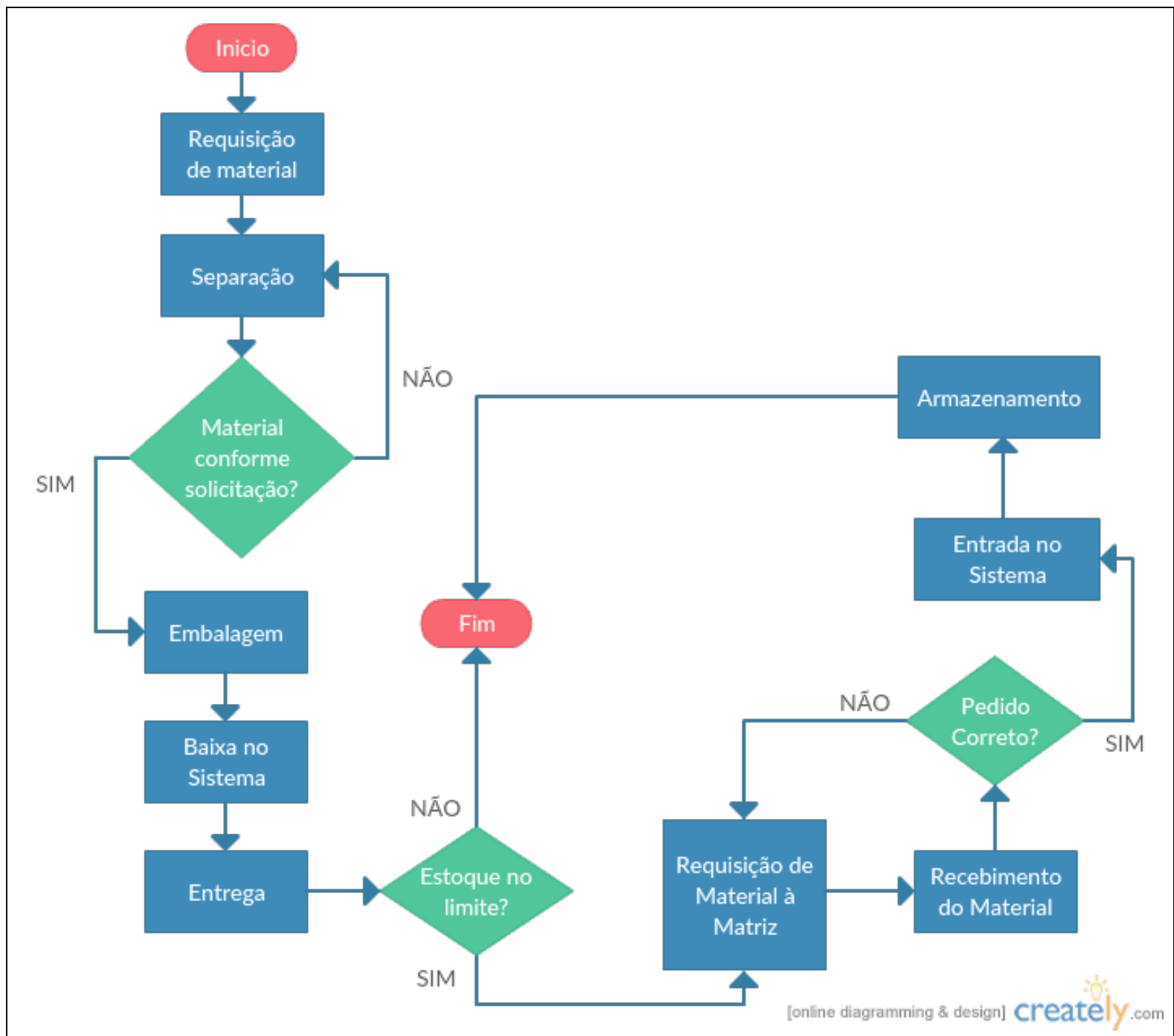

Figure 1: Process Flowchart. Source: Prepared by the authors

To get the transport branch is unloaded, checked and stored and made the accepted into the system, if there is some divergence in receiving notes are made to subsequently make the adjustments due as shown in Figure 1 flow.

\subsection{Discussions}

The greatest difficulty faced by the warehouse sector is related to the time spent for the process of separation and distribution of items to other departments. On average it is necessary to use about $40 \%$ to $50 \%$ of the time hours available only for this step of separation and distribution.

The back room of the hospital is responsible for supplying all the sectors and stocks, at a given moment are many requests to separate causing the number of employees is not enough for so many activities. In the days that went to search the back room had 4 employees, these being: 1 Warehouse Assistant, auxiliary 2 
INDEPENDENT JOURNAL OF MANAGEMENT \& PRODUCTION (IJM\&P)

http://www.ijmp.jor.br

v. 9, n. 5, Special Edition IFLOG 2017

ISSN: 2236-269X

DOI: 10.14807/ijmp.v9i5.793

warehouse and 1 assist, support this task of conducting deliveries in the sectors and give the necessary support to the warehouse.

During the study was possible to highlight the importance in optimizing the time for completion of the process of separation and distribution, since this is a vital task for fitness to the tabling deadlines, in order to prevent falls at the service level. Thus adopted mathematical models and quantitative methods focused on logistics, along with a Microsoft Excel add-in, the Solver program as an alternative solution to the problems of reducing drive time using the method of least Way.

Drive time optimization passes by calculation that estimates should be interpreted for the full management of warehouse area. In this case as a first step, conducted an analysis of the routes to find the shortest route, later devised a graph and a Modeling of the process.

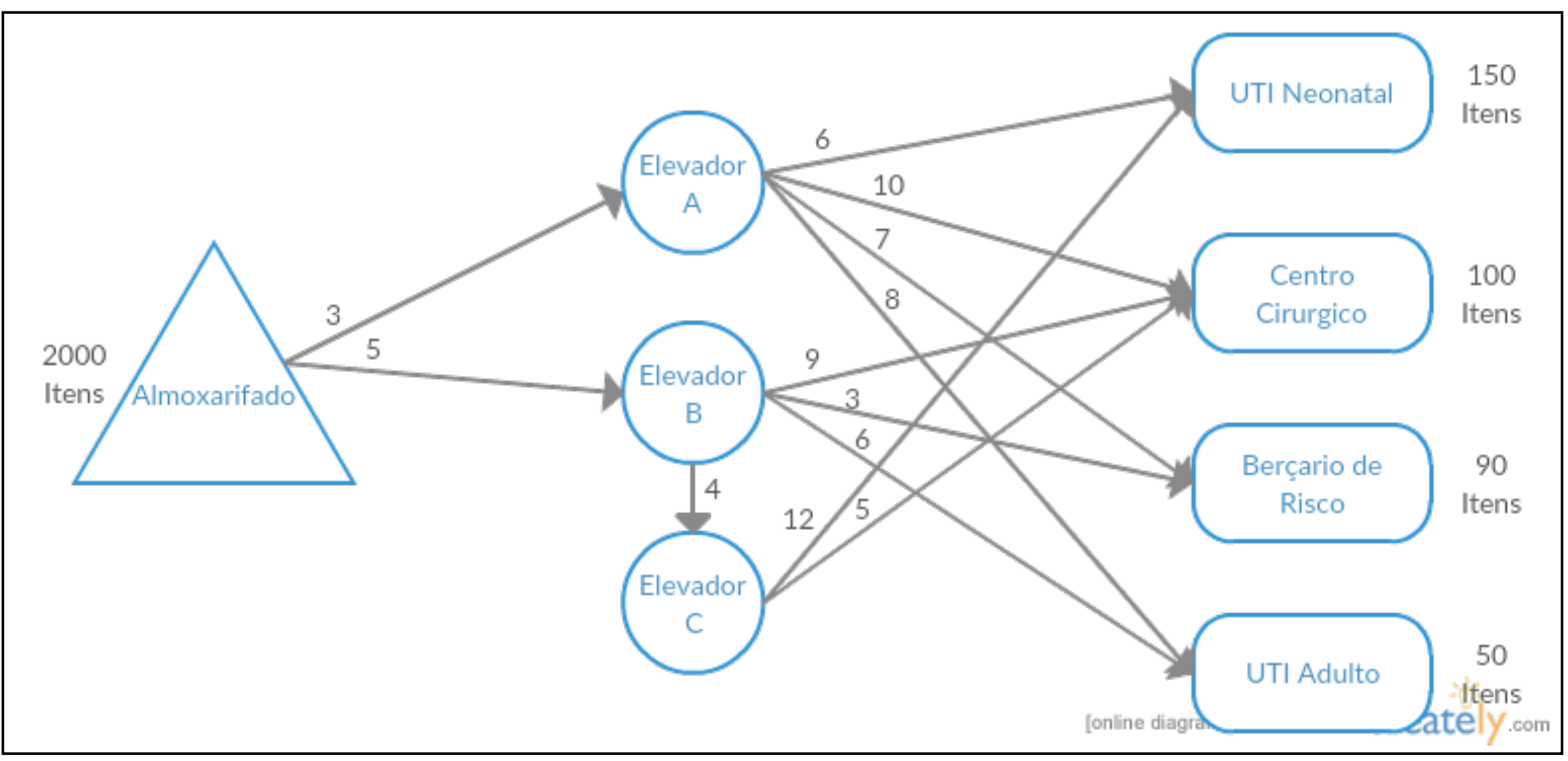

Figure 2: Distribution routes Graph

Source: Prepared by the authors

Figure 2 represents a reference for the elaboration of mathematical model, showing the flow of distribution routes. Distribution routes: graph consists of a diagram (diagram) formed by a set of vertices (nodes) and arcs (edges), with each ARC associated (linked) to one or more vertices.

In that, the vertices/nodes are the sectors or Hospital departments (Storeroom, Elevators, ICU, nursery, etc.) and arcs/edges are traversed paths between the source and the destination. 
Mathematical modeling is the art (or attempt) to describe mathematically a phenomenon. So to build this mathematical model was followed a few steps:

1) Step: Define what are the decision variables, in this case are the paths to be chosen, being (i) and (j) the source destination (xij is the path between the source and destination $\mathrm{j}$ ).

So $=x_{12} ; x_{13} ; x_{25} ; x_{26} ; x_{27} ; x_{28} ; x_{34} ; x_{36} ; x_{37} ; x_{38} ; x_{45} ; x_{46}$.

2) Step: Define the objective function, in this case the goal is to optimize the movement of materials, i.e., minimize the time of distribution of the items.

$Z \min =3 x_{12}+5 x_{13}+6 x_{25}+10 x_{26}+7 x_{27}+8 x_{28}+4 x_{34}+9 x_{36}+3 x_{37}+6 x_{38}+12 x_{45}+$ $5 \times 46$

3) Step: Define the restrictions following the premise of the Smallest Way, noting that only you can choose an output on each node.

Thus 1 node $=x_{12}+x_{13}=1$

2 node $=x_{12}-x_{25}=0$

3 node $=x_{13}-x_{34}=0$

4 node $=x_{34}-x_{45}-x_{46}=0$

5 node $=x_{25}+x_{45}=1$

6 node $=x_{26}+x_{36}+x_{46}=1$

7 node $=x_{27}+x_{37}=1$

8 node $=x_{28}+x_{38}=1$

4) Step: put the data in Microsoft Excel, it should be noted that during the study recognized the need to focus on the problem of shortest paths for source and destination unique, given the Graph of Distribution routes devised other Graphs for each separate target, since applying the Lower Path of a single source to multiple destinations is unworkable. 
INDEPENDENT JOURNAL OF MANAGEMENT \& PRODUCTION (IJM\&P)

http://www.ijmp.jor.br

v. 9, n. 5, Special Edition IFLOG 2017

ISSN: 2236-269X

DOI: 10.14807/ijmp.v9i5.793

Table 1: Smaller Target Path Modeling UTI neo

\begin{tabular}{|lcccccccc|}
\hline & $x 12$ & $x 13$ & $x 25$ & $x 34$ & $x 45$ & & & \\
& 1 & 0 & 1 & 0 & 0 & & \\
Zmin & 3 & 5 & 6 & 4 & 12 & 9 & & \\
Nó1 & 1 & 1 & & & & 1 & $=$ & 1 \\
Nó2 & 1 & & -1 & & & 0 & $=$ & 0 \\
Nó3 & & 1 & & -1 & & 0 & $=$ & 0 \\
Nó4 & & & & 1 & -1 & 0 & $=$ & 0 \\
Nó5 & & & 1 & & 1 & 1 & $=$ & 1 \\
\hline
\end{tabular}

Source: Prepared by the authors

Table 1 Minor Modeling target path UTI Neo: in this table are presented all the data collected, the decision variables, objective function and constraints to the destination route UTI Neo.

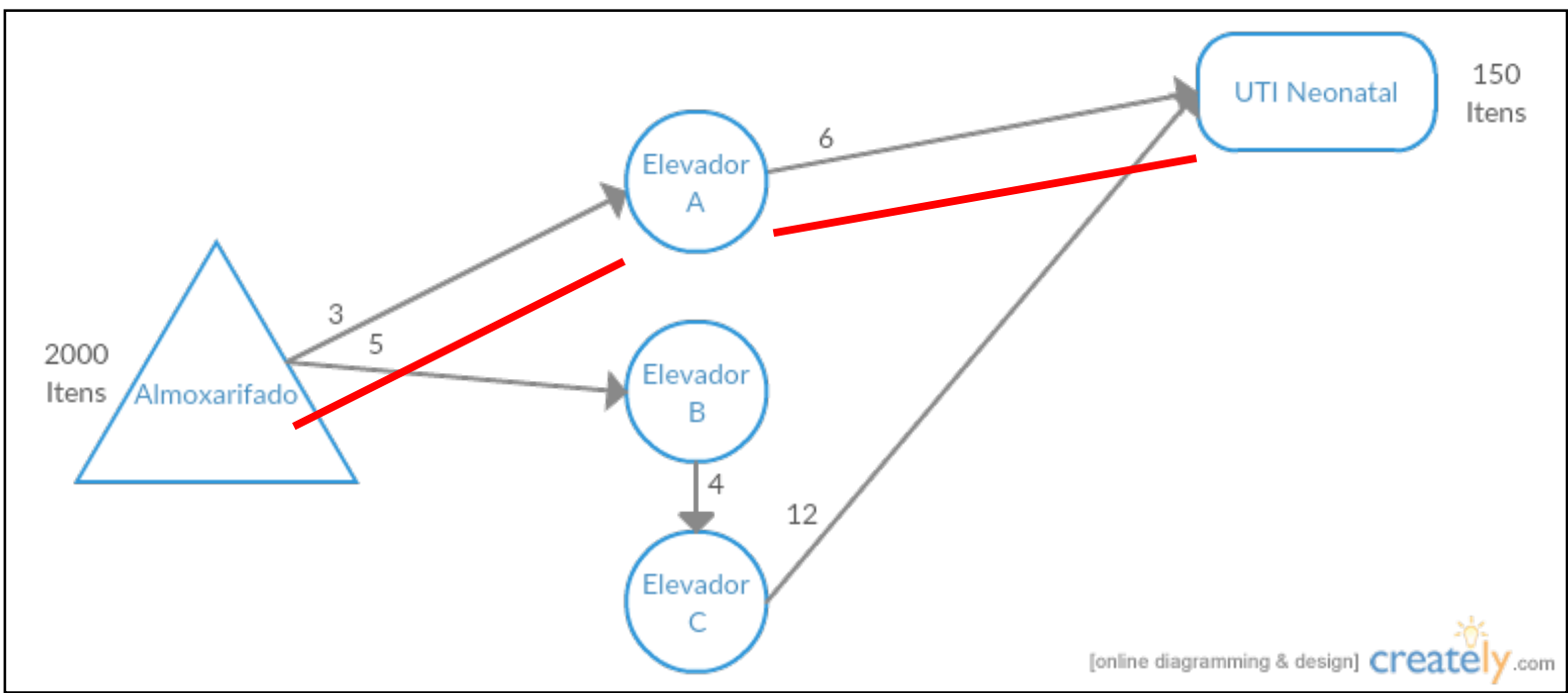

Figure 3: Solution target Routes Graph UTI Neo

Source: Prepared by the authors

After you apply the Microsoft Solver method of Smallest Way We obtained the optimal solution of 9 minutes represented in Figure 3.

Destination Routes graph UTI Neo and solution: it constitutes a diagram similar to the first graph, also consists of a set of vertices and arcs, with the difference that this contains only a destination, the Nicu. The optimal solution of the path traced in red, the warehouse through the elevator up to the Nicu and used 9 minutes. 
INDEPENDENT JOURNAL OF MANAGEMENT \& PRODUCTION (IJM\&P)

http://www.ijmp.jor.br

v. 9, n. 5, Special Edition IFLOG 2017

ISSN: 2236-269X

DOI: 10.14807/ijmp.v9i5.793

Table 2: Minor Surgical Center Destination Path Modeling

\begin{tabular}{|lcccccccccc|}
\hline & $x 12$ & $x 13$ & $x 26$ & $x 34$ & $x 36$ & $x 46$ & & & \\
& 1 & 0 & 1 & 0 & 0 & 0 & & & \\
Zmin & 3 & 5 & 10 & 4 & 9 & 5 & 13 & & \\
Nó1 & 1 & 1 & & & & & & 1 & \\
Nó2 & 1 & & -1 & & & & 0 & $=$ & 0 \\
Nó3 & & 1 & & -1 & -1 & & 0 & $=$ \\
Nó4 & & & & 1 & & -1 & 0 & $=$ & 0 \\
Nó6 & & & 1 & & 1 & 1 & 1 & $=$ & 1 \\
\hline
\end{tabular}

Source: Prepared by the authors

2 Minor Modeling table destination path the surgical Center: in this table are presented all the data collected, the decision variables, objective function and constraints to the destination route.

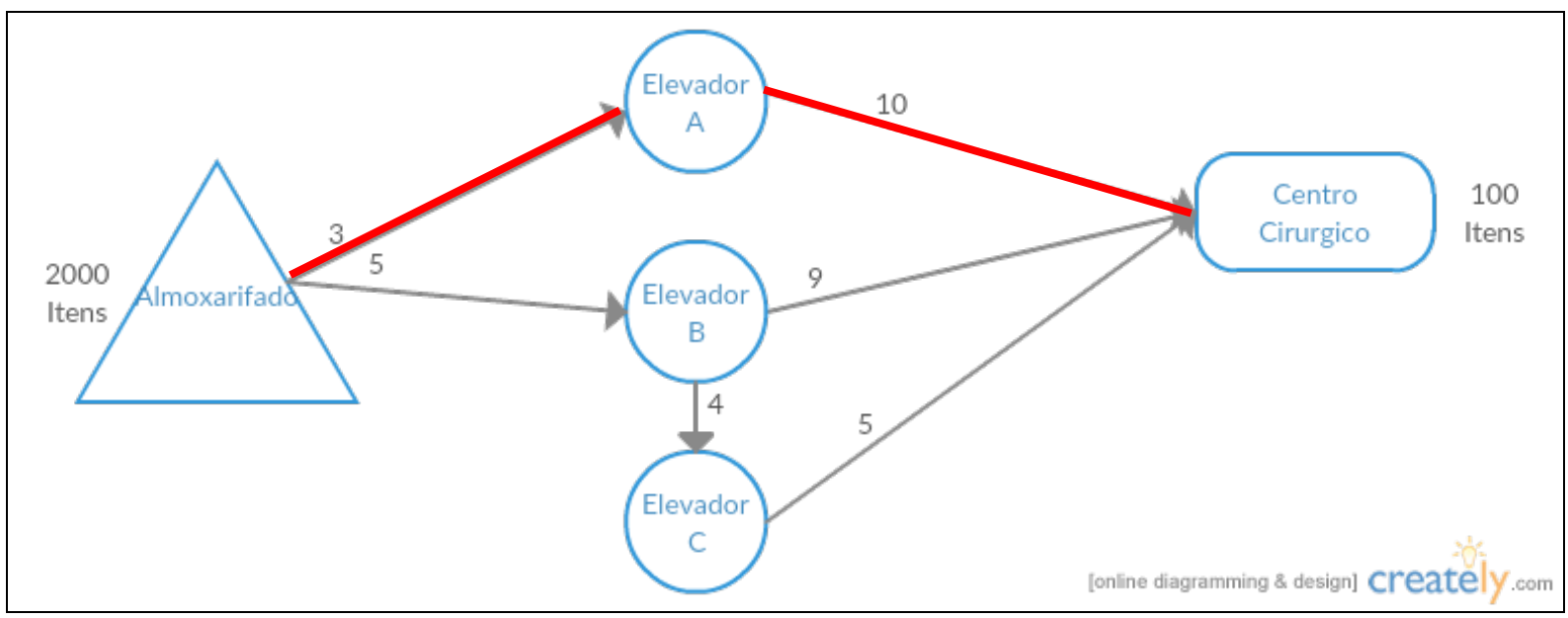

Figure 4: Solution target Routes Graph

Source: Prepared by the authors

After you apply the Microsoft Solver method of Smallest Way We obtained the optimal solution of 13 minutes represented in Figure 4.

Destination Routes graph Surgical Center: follows the same principle of other Graphs, also consists of a set of vertices and arcs, with the difference that this contains only a destination, the Surgical Center. The optimal solution of the path traced in red, the warehouse through the elevator up to the Surgical Center and being used 13 minutes. 
INDEPENDENT JOURNAL OF MANAGEMENT \& PRODUCTION (IJM\&P)

http://www.ijmp.jor.br

V. 9, n. 5, Special Edition IFLOG 2017

ISSN: 2236-269X

DOI: 10.14807/ijmp.v9i5.793

Table 3: Smaller Target Path Modeling risk Nursery

\begin{tabular}{|lccccccc|}
\hline & $x 12$ & $x 13$ & $x 27$ & $x 37$ & & & \\
& 0 & 1 & 0 & 1 & & & \\
Zmin & 3 & 5 & 7 & 3 & 8 & & \\
Nó1 & 1 & 1 & & & 1 & $=$ & 1 \\
Nó2 & 1 & & -1 & & 0 & $=$ & 0 \\
Nó3 & & 1 & & -1 & 0 & $=$ & 0 \\
Nón & & & 1 & 1 & 1 & $=$ & 1 \\
\hline
\end{tabular}

Source: Prepared by the authors

Table 3 Smaller Nursery destination path Modeling of Risk: in this table are presented all the data collected, the decision variables, objective function and constraints to the destination route Nursery.

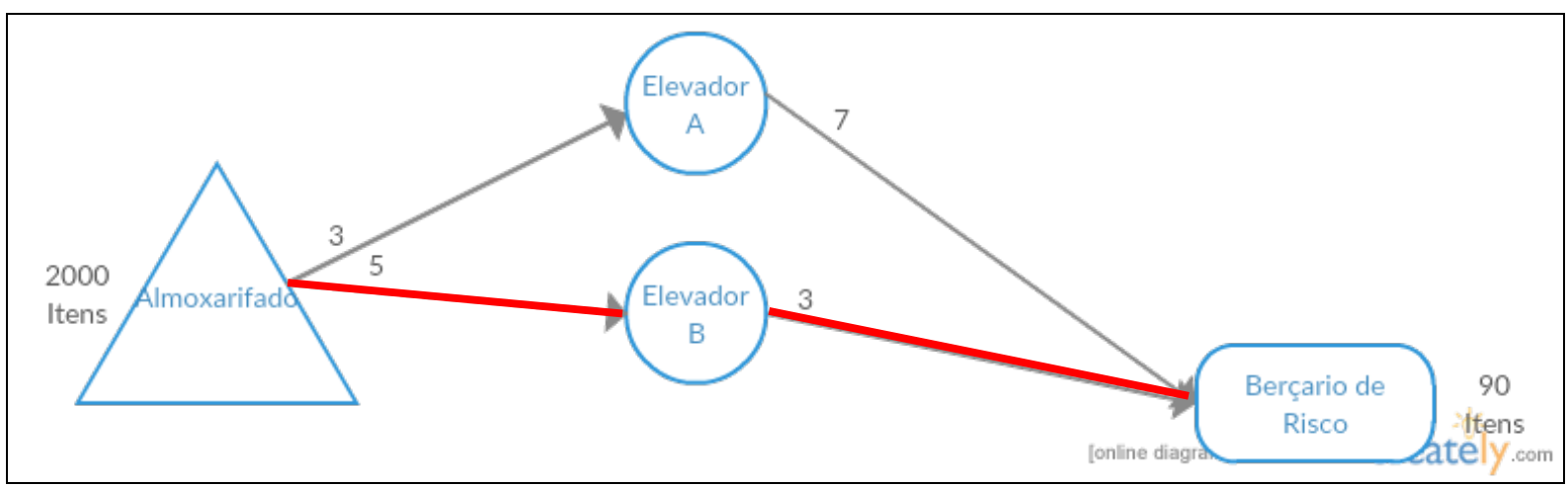

Figure 5: Solution target Routes Graph Nursery

Source: Prepared by the authors

After you apply the Microsoft Solver method of Smallest Way We obtained the optimal solution of 8 minutes represented in Figure 5.

Destination Routes graph Nursery: follows the same principle of other Graphs, also consists of a set of vertices and arcs, with the difference that this contains only a destination nursery. The optimal solution of the path traced in red, the warehouse through the Elevator B to the nursery and used 8 minutes. 
DOI: 10.14807/ijmp.v9i5.793

Table 4: Smaller Target Path Modeling Adult ICU

\begin{tabular}{|lccccccc|}
\hline & x12 & x13 & x28 & x38 & & & \\
& 0 & 1 & 0 & 1 & & & \\
Zmin & 3 & 5 & 8 & 6 & 11 & & \\
Nó1 & 1 & 1 & & & 1 & $=$ & 1 \\
Nó2 & 1 & & -1 & & 0 & $=$ & 0 \\
Nó3 & & 1 & & -1 & 0 & $=$ & 0 \\
Nós & & & 1 & 1 & 1 & $=$ & 1 \\
\hline
\end{tabular}

Source: Prepared by the authors

Table 4 Minor Modeling Adult ICU destination path: in this table are presented all the data collected, the decision variables, objective function and constraints to the destination route Adult ICU.

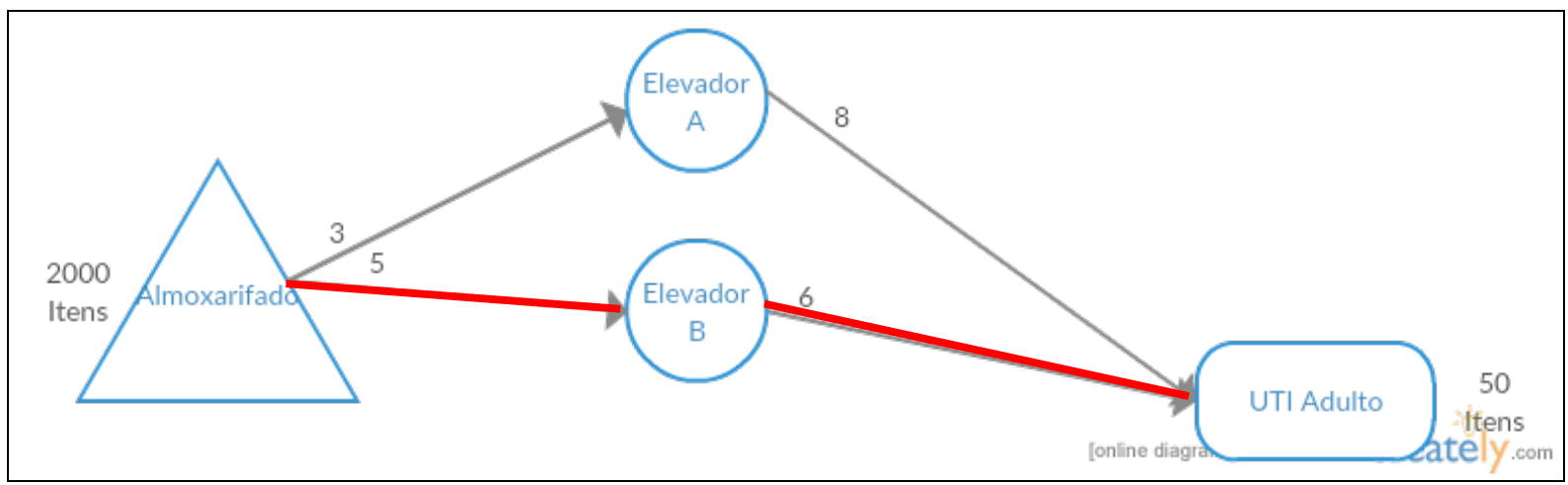

Figure 6: ICU Adult Destination routes Graph

Source: Prepared by the authors

After you apply the Microsoft Solver method of Smallest Way We obtained the optimal solution of 11 minutes represented in Figure 6.

Destination Routes graph ICU adult follows the same principle of other Graphs, also consists of a set of vertices and arcs, with the difference that this contains only a destination, the Adult ICU. The optimal solution of the path traced in red, the warehouse through the Elevator B to the Adult Intensive Care Unit and being used 11 minutes.

If we consider that the process of distribution of items held by any route and on average spent themselves 56 minutes (round trip) to complete the process. With the implementation of the proposed quantitative methods will be used a single route for each sector and will be spending a total of 41 minutes (round trip), having a $27 \%$ gain. 
DOI: 10.14807/ijmp.v9i5.793

\section{CONCLUSIONS}

The present study had as purpose to analyze the importance of the application of quantitative methods in inventory management, whose methodology was characterized by the application of a case study in the MPMP Hospital.

It can be concluded that the adoption of quantitative methods applied on materials handling is critical for public and private organizations to obtain satisfactory results in the managerial decision-making process. In the models presented and by the adoption of the Smaller Way, the quantitative models for inventory management can be employed to reduce possible improper handling of materials.

Through the benefits presented in the case study, it appears that the implementation of this procedure is quite simple and the Hospital can deploy it with confidence that improvements will occur in their activities.

It should be noted that the study focuses only on the areas considered most critical of the Hospital, that is, if these methods are applied in other areas of the Hospital rapidly gains distribution without doubt will be bigger. With the expected improvements, the Hospital can qualify the warehouse sector, increasing efficiency and the level of service.

\section{REFERENCES}

ARNALD, J. R. T. (1999) Materials Management. São Paulo: Atlas.

BAKER, P.; CANESSA, M. (2009) Warehouse Design: a structured approach.

European Journal Of Operational Research, Atlanta, v. 193, n. 2, p.425-436, 01 mar.

BALLOU, R. (2001) Supply chain management: planning, organization and business logistics. 4. ed. Porto Alegre: Bookman.

BALLOU, R. H. (2006) Supply Chain Management. São Paulo: Saraiva.

BOWERSOX, D.; CLOSS, D. (2001) Business Logistics. São Paulo: Atlas.

FLEURY, P. F. (2007). Business Logistics: a brazilian perspective /

(organização) Peter Wanke, Kleber Fossati Figueiredo. - 1. ed. - 9. reimpr. - SP: Atlas - (Collection COPPEAD Administration).

FURTADO, M. R. (2006) Application of prediction model of Total demand in Belgium Accredited ready. Monograph, Universidade Federal de Juiz de fora.

GIL, A. C. (1991) Methods and techniques of social research. 3. ed. São Paulo: Atlas. 
GU, J.; GOETSCHALCKX, M.; MCGINNIS, L. F. (2007) Research on warehouse operation: A comprehensive review. European Journal Of Operational Research, Atlanta, v. 177, p.1-21.

HILLIER, F.S.; LIBERMAN, G. J. (2010) Introduction to operations research. $8^{a}$. Edição. São Paulo: Mc Graw Hill.

KOSTER, R., DUC, T. L.; ROODBERGEN, K. J. (2006) Design and Control Of Warehouse Order Picking: A Literature Review. European Journal of Operational Research, n. 182, p. 481-501.

LUNA, M. M. M. et al. (2011) Layout of a Warehouse: an application of integrated logistics Tools and MTM. XVIII SIMPEP: Symposium on Production Engineering, Bauru, v. 1, n. 1, p.1-13, nov.

MOURA, C. E. (2004) Inventory Management. 1a . Edição. Rio de Janeiro: Editora Ciência Moderna Ltda.

MOURA, R. A. (2005). Systems and techniques for handling and storage of materials - 5.ed.rev. - São Paulo: IMAM - (Série manual de logística;v.1)

PRAZERES, T. F.; LEAL JUNIOR, I. C.; GARCIA, P. A. A. (2010) Grey Relational Analysis and Hierarchical Analysis method: A comparative study applied to the case of steel material handling and storage. VII SEGeT-Symposium on excellence in management and technology. Resende/RJ.

SANTANA, S. L. T. Analysis of the management system of Warehouse stock of a multinational Agricultural branch. Centro de Ensino Superior dos Campos Gerais - CESCAGE, Ponta Grossa, n. 8ª , p. 18, Jul - Dez 2013.

SILVA, R. M. (2016) Logística hospitalar. Disponível em:

<http://www.administradores.com.br/artigos/negocios/logistica-hospitalar/98153/>. Acesso em 09 de Junho de 2017.

TADEU, H. F. B. (2008) Quantitative Methods Applied in Inventory Management: a practical case study for Organizations. São Paulo: Mundo Logística, ano II.

ZHANGA, G. Q.; LAIB, K. K. (2010) Tabu search approaches for the multi-level warehouse Layout problem with adjacency. Engineering Optimization, v. 72, n. 8, p.775-790, ago. 